\title{
On Development of the Artistic and Figurative Content in Music Performance
}

\author{
Mark Berlyanchik \\ Russian State Specialized Arts Academy \\ Moscow, Russia \\ e-mail: mberl@mail.ru
}

\begin{abstract}
The article follows important stages of the historic process of the problem actualization and discovery of the artistic sense in music composition. Different solutions are analyzed.
\end{abstract}

Keywords-music composition; music content; artistic education; performer's intonation

\section{INTRODUCTION}

The nature and the problems of the artistic and figurative side of the musician-performer's activity, especially instrumental performers, attracts more and more attention in our time, becoming a topic of consideration for concert performers, critics, music scientists and progressive teachers. This interest is not occasional: it is closely connected to the aspiration to realize the spiritual meaning of music, of art, its unlimited resources of showing the human spiritual state and human aspirations.

In other words, it has become obvious that the problems of the development of the figurative senses of music compositions and the discovering of the essence field of its artistic interpretation finally disappear in performance. According to B.V. Asafiev «...music's life is in its performance, in pronunciation, intonation for the listeners».

Today we may state that these problems are not only real, but in the XXIst century become more important for the world's spiritual and humanitarian development. Yet, they've been attracting the attention of the leading musicians during all times of the historical music development.

Speaking about a particular loss of the great performing traditions' spiritual intentions of interpreted music it is important to know that the roots of this phenomenon go very deep. They are connected to a particular lop-sidedness of the interior processes of the essence of the music performance and a loss to the general tendencies of the development of the human civilization in the XXth century.

At the very beginning of the last century an outstanding Swiss music theorist Ernest Kurt complained: «Musical understanding is kind of covered by the sounds, the theory hasn't lost an ability to hear the unheard, which is hidden behind and thus to cover the processes, seen through the sounds and accords. » $[6,76$; Italics by the present author -
M.B] We think that this wise opinion in a great way considers modern music theory (particularly to the very part that functions in educational spaces) in its widest meaning, including the theory of performers' art, music teaching and different instrument music performance.

True, the theory and methodology of music performance in its historic growth as a science and an educational subject always received much more attention in regards to the means and not the objectives of music performance art: its psychological and motorical nature, the physiology, acoustic and psychological specifics of the performance, the connection of sound intonation ideas with movement processes, the study of different kinds of instrumental texture, technique, etc. There were only some sporadic studies of the main artistic, figurative, poetic and finally spiritual side of music performance.

\section{HISTORICAL EXAMPLES OF THE IMPORTANCE OF ARTISTIC CONTENT}

Yet, music performance history practice is familiar with some other brilliant facts. Here are some examples from different epochs and performance branches.

The fist part of the XVIIth century. The famous violinist and music teacher Francesco Gemiani recommends his students in his «School» (1730), according to the wellknown effects system, to fantasize about different tragic events like natural disasters, shipwrecks, earthquakes, losing beloved friends, etc. in order to excite a strong emotional impact. In his opinion this was the correct way to express a particular emotion in music performance.

Another famous violin teacher, Leopold Mozart's genius father Wolfgang, in his «Fundamental violin school» (1756) wisely opposes a thoughtless soloist, a trained canary (some modern nominators may be remembered here!) to a thinking orchestrator, used to «looking deeper into all detail and knowing the different morals of music». [quoted by 7].

In the middle of the XIXth century Richard Schumann, as if developing these thoughts, stood for the semi-artistic orientation in music performance, stating that «an educated musician may with the same luck study Raffael's Madonna», like an artist may listen to Mozart's symphonies, since «for 
an artist a poem turns into a picture and a musician turns a picture into a sound» [quoted by 2,84 ].

At the beginning of the XXth century the French pianist and music teacher Alfred Corto insisted on recommending his students to compose and to literary decorate the figurative programs of the performed compositions. At the same time, opposed to the intentions of some students to use the prepared plots by the Master himself (Corto's comments to Chopin's, Debussy's and Schumann's compositions and other authors), he noted: «being flattered by their approval, I would prefer that they would address their own imagination or their own sensitivity rather than a prepared interpretation» [quoted by $2,131-132$, italics by the present author - M.B.] Then, moving forward, let's note that there is a firm position in these words concerning the originality and the poetic content of the music composition.

At the very beginning of the same century (1905) Jozhef Ioahim, called «the father of interpretation art» in the violin performance history, used to say that at the very beginning of the violinist formation stage «considerate expression and performance are not coming from within, but should be organically connected to the whole performance.» At the same time he said that he was speaking «not only about the student being able to produce his small pieces at this very stage, but about a teacher being able to excite his artistic thinking» [quoted by 2,131-132, italics by the present author - M.B.].

\section{LEOPOLD AUGER AND THE DEVELOPMENT OF INTONATION THEORY}

A special place among the teachers having educated great violinists belongs to Leopold Auger. In his activity, according to $\mathrm{V}$. Yu. Grigoriev, two stages were brightly marked: the first, during which Auger, following the traditions of the violin pedagogics, paid special attention to the technical development, and the second, when he turned to the artistic side of the performance, to the objective education of the creative part and the development of a unique individuality of every student. It was in this particular period when from his class there appeared a number of world-famous stars - Yasha Heifets, Cecilia Hansen, Yefrem Cimbalist, Miron Polyankin, etc.

It is typical that in his book «My violin playing school» Auger formulates clearly the basic demands for the violinists to be more expressive and to get away from senseless melody performance, which, in his opinion is typical for young performers. This is especially important for the melody, the music's soul, where expressive incorporation is connected to the violin's very nature...

Let us quote his words: «The violinists», as Auger wrote ironically, - «enjoy that they play notes, not paying attention that the melody means much more than a number of extracted sounds» $[1,89$, italics by the present author $M . B$.] Of course, Auger could not know the intonation theory, which was created much later by B.V. Asafiev and
B.L. Yavorsky. But some expressions of the great teacher have been anticipated it. Really, when he blames the violinists that the visual notes are transformed into signals of absolutely different nature, which mean performing activity («play notes as they were written»), we can speak about the lack of structure when performing the most important intonation content. It is the necessary to prepare the music sounds of the unheard poetic content, which was mentioned by Curt in the above expression.

Auger, nevertheless, did not restrain himself to the critical sententious to the violinists. We should mark his extraordinary sharp thoughts that anticipated modern understanding of the essence and structural laws of the melody formation of the musical-artistic image, which explain that «a melody is composed of the separate melodic unities, which are independent from one another and connected to one another, demanding diverse rhythmic and emotional accentuation» $[1,89$, italics by the present author - M.B.].

Many things are interesting in his words. The true dialectics of learning the nature of the melodies nature (according to Mazel, original intonation-genre complexes), which have the historic field of different semantic meanings in European music culture are analyzed in depth. Auger justly considers such intonations («independent and interconnected melodic unities! ») to be structural points of the musical and artistic process. Extracting the sensecorrecting function from the rhythmic component is also very wise.

It is becoming clear that in Auger's teaching expressive understanding and melody pronunciation began from artistic understanding of the content of the slightest particles melodic intonations. Its expressiveness, in Auger's understanding, did not limit the expression of the illogical, tone and sound-dynamic and articulate performance means which were marked by the author as a general demand of «diverse emotional accentuation». The same was mentioned by other famous performers. M.L. Rostropovich, for instance, always showed to his students the expressiveness of the melody through the composing intervals' dependence of the rises and falls of performer's emotions.

Thus an approach to the melodic intonation in Auger's pedagogics was marked, which later was developed in Russian music science. It was an intonation theory in the melody theory, the methodology of complete analysis and its other branches, which still didn't find enough realization in music performance and music teaching. That is why they didn't influence the music educations' wide practice.

\section{SOURCES OF ARTISTIC INTONATION}

In particular, one important question was not theoretically covered: which sources could be used to get the artistic content of a music-intonation process? In other words, what inspires the artistic imagination of a music performer? There are very sporadic subjective expressions 
of important personalities - performers and teachers. For example, there's an opinion that a nutritious environment of an emotional-figurative perception of a musician may be not only influenced by different artistic events, but also by his life impressions. D.B. Shafran in his conversation with Prof. G.M. Tsypin said: «Which impressions do you mean? I ... mean not only musical ones. If I were a teacher, I would constantly lead the student's attention to everything that surrounds their life. This is art, but also it is people with all their joys and sorrows. And the nature... I would try to express everything with music. » $[8,142]$.

Summing up all of the above, one may say that the problems of music's artistic content and its performanceinterpretation never left the vision of the great teachers and performers. It is a great pity that their basic ideas are not accumulated by the majority of music performers in the existing three-stage structure "school-college-university» and that they do not adapt to this rather canonized area of music performance, which is called «the method of playing a music instrument» (a piano, a violin, an accordion).

Today we harvest the results of it... Russian performance culture up until recently reflected the shine of the previous blossom, when great masters were keeping the great spiritual conquests of Russian art of the 2nd half of the XIXth and the first part of the XXth century. Modern generations of young performers feel the expansion of modern media and other technological achievements. As a result the content, the artistic-figurative and the spiritual part of music in its aesthetic importance may be lost or weakened. The social-cultural responsibility belongs to performers, who have to animate the intonation layer of music which is the closest to the content (V.V. Vanslov).

\section{RECENT DOMESTIC LITERATURE}

Still, for justice sake we should say that not only in some expressions of the creative practice, marked above, but also in the Russian music performance theory of a particular period (about 1970s) there appeared and slowly increased an aesthetic, artistic and thematic approach to performance art and the productive performance of a musician as an interpreter. We think that there was a critical realization of the experience of performance of the Soviet instrumentalists in the first Tchaikovsky's contests, which were acutely discussed.

It is interesting that G.M. Kogan, the author of the famous book «At the master's gate» which was presented as an apology to the so called psycho-technical performance school and took care first of all of the connections between the interior ideas of the texture compositional structures of notation with its instrumental (movement) incorporation, published another book in 1975 under the wonderful name of «On Intonation of the Content of the Piano Performance» [5].

Modern psychophysical direction in performance theory (A. Birmak, O.F. Shulpyakov, V.P. Sradgiev, B.I. Talalay, etc.) in which complex interconnections between the movement and sound ideas of a musician were studied, moved towards an idea of artistic technique, which was meant for the development of intonation and even wider to the content determinations of the performed composition. It is important that the second big work of this kind is O.F. Shulpyakov's «Music Performance Technique and an Artistic Image», where a concept of the necessity of technical and technological analysis was marked through the artistic synthesis [9].

However, this concept has not given the answer to the marked questions; neither did the study of aesthetics of performance art. Yet, in the context of the latest work (G.I. Gilburda, E.G. Gurenko, S.H. Rappoport, T.B. Cherednichenko, etc.) a lot of phenomena and ideas were discussed, which were important from the position of the content of the performance process: the nature and essence of an artistic interpretation in performance, the secondary nature of the work of the musician-performer and the role of an artistic idea in the creative idea of the performer. Such questions were discussed by theoreticians of music performance such as N.P. Korykhanovs, A.A. Nikolaev, S.H. Rappoport, V. Yu. Grigoriev, by the present author, etc. The position of multiple interpretations and the development of its artistic content in different contexts were covered.

\section{REALIZATION ISSUES OF A BROADER ACKNOWLEDGMENT OF THE IMPORTANCE OF ARTISTIC CONTENT}

Summed up, one may say that the historic-theoretic music studies, music aesthetics as well as the music performance science, during the last decade created important prerequisites for dealing with the problems of the music content and for incorporating its artistic image in the process of the musician's education - both of a professional and a competent amateur. Just question keeps appearing: Why is there an obvious gap between a wide practice and the musician's preparation and instrumental performance education in the area of performance art and music in general and also in neighboring (but also very important) disciplines.

The answer to this question is obvious. The main obstacle, from my perspective, is the passiveness of the performers, who prefer to follow the tradition of practice and methodology instead of trying to get the maximum from modern science's achievements. Yet, it is possible that they are restricted by some fears if the implementation of the new ideas would lead to the opposite results - the decrease of the quality of professionalism and performance? Such fears have their grounds if they are voiced by young musicians, which number is threateningly increasing.

Thus the problem of incorporating multiple music contents into the process of performance and listening is closely connected to a much deeper problem in music practice of the fundamental kind. First of all, it is the 
problem of the value orientation in art (and in life!), directed towards the bright impression only from outside light and in the other to discover interior spiritual values. We think that it would be rather difficult to care about the true understanding of the artistic-figurative content of the music outside the personal and philosophy perception.

\section{PROPOSED SOLUTIONS}

Now let's turn to some theoretical and practical ideas concerning some possible steps for the overcoming of the above characterized situation existing in the music education. Recently in music studies and music teaching a movement has began in different directions, which may be considered an intention to recuperate the lost significant importance of music in personality education.

Among these tendencies there's an actualization of artistic content research, in particular an initiative of creation of a special branch of music science - the theory of music content and the efforts for its implementation to all the stages of music education (V.N. Kholopov, L.P. Kazantseva, A.Yu. Kudryashov, etc.). We'll come back to this issue at the end of our study. Let's express some general considerations.

While studying the area of music interpretation there's a need to specify the used terminology. Indeed, when they speak about the content of a real music phenomenon (composition, composer's work, epoch style), there may appear an idea of its ambiguity, the only correct understanding, quite a true fabula. Yet, as it is commonly known, the field of content interpretations of a performed composition (especially a musical one, remembering A. Corto's recommendations) is very varied. That's why we would rather speak about not the content, but the content phenomenon of a music work and music in general.

Besides, when speaking about a particular music content, there is a question: is the definition of «musical» synonymous to «artistic»? It is usually not. From our perspective, in this context, «musical» is meant as specific «sound-intonation». It means that the music expresses some content and not the expressed. In semiotics terms it's a sign, not a detonate (the marked one).

In this regard let us come back to the issue of the structure of creative activity of a musician-performer. It can generally be represented like a three-component system composition - a triade, consisting of three text-phenomenal content layers. 1) associative-figurative, artistic and poetic, so the layers which have a considerably higher sense meaning than the others; 2) music-intonation (sound), in which the previous layer of music content is ciphered according to the semantic-semiotic rules, historically formed in the European music culture (according to B.V. Asafiev, the intonation vocabulary of the epoch); 3) mono-plastic, thanks to which both the previous layers of the musician's activity become a real voice or instrument sound. At the same time, it is theoretically and practically important to understand this triade as structures concreted by varied elements.

For the didactic meaning it is very important that, according to systemology, such systems are open ones: their «entrance» to the structure of any student, including the beginning and the upper ones, is possible through every one of them. For a performer and a teacher is essential to realize that the three marked basic layers of a musician's performing activity are incorporated differently in different material and ideal structures.

So, the upper associative-figurative layer in the maximum measure remains a virtual one, but exists in the ideal world. But sometimes it is spoken (like Corto) and then, according to P. Ya. Galperin's psychology theory about the stage formation of intellectual thinking and the neuro-linguistic theory, it becomes materialized. As far as the other layers of performing activity go, the intonation one and the motoric one, they are also characterized by the flexible transitions form the material world to the idealized one. We are speaking about the thought anticipation (according to Teplov, imaginariness) of the intonationsound text of music work, or, let's say, of the motoric actions - thinning images and presentations as instrumental-playing actions.

The main thing is that the completeness of the characterized triade in professionally complete performance and in educational practice should not be broken. In David Oistrach's class, according to his students and colleagues, the «moments of technology and interpretation were never divided. Everything was in constant unity, in the name of more complete development of the depth of the music content» [quoted by 2, 92].

Logically, in order to overcome the delay of the artisticfigurative side in modern music performance and teaching, we should consider the factor of its completeness with the two other components of the marked completeness. These are musical-intonation (sounding) text with the corresponding of a complex of instrumental-playing movements. In other words, when a musician perfects his movement performance skills and is looking for adequate methods of sound presentation such as some complicated strokes and articulation nuances, he is in fact moving towards a deeper understanding of the artistic-figurative content of the composition and its incorporation for the listener.

From this perspective, a great interest is aimed towards home technology classes of David Oistrach [4] described by $\mathrm{V} . \mathrm{Yu}$. Grigoriev. It may be called a method of the 'reintonation' (E.A. Ruchyevskaya's term), when in an experimental way a number of intonation versions is created, which provide certain nuances. In the famous violinist's classes «there were no multiple repetitions of the same passages. All versions, produced by his bow, were so different and unique that they seemed to be different music. A music phrase sounded silently or harshly, or 
contemplatively or dynamically. Music colors changes instantly - Oistrach was searching. He was passing all the spectrum of all the possible music phrase incorporations, sound solutions, rhythmic sharpness or perfection of the sound. Suddenly a piece sounded as a concert performance. A pause followed. David Fedorovich listened to the class recording with attention».

The quoted description of the original method of work of the greatest performers of the XXth century with music composition allows us to conclude that the highest aim of the true artist should be the discovery of variations of fabula interpretation of the music composition (V.V. Medushevsky).

In other words, we may ask: is it possible to educate musicality and music-figurative imagery of a rather high level, which would allow us to use this method in wide performance and education practice? Let us remind that, according to B.M. Teplov, a specific characteristic of humankind, called musicality, is the sensation of emotional sensitivity in music.

Yet, considering the variability of poetic music's content, the criteria of music sensitivity looks lop-sided. For the active search for potentially possible variations of its artistic content not only emotional reactions and aesthetic remarks are necessary, but also a considerable intellectual level. And it demands not only accumulation and consideration of the different musical sound experiences, but also the forming of the adequate psychological qualities, the richness of life impressions of a different kind, harmonizing two spheres of a music personality - emotional and intellectual.

In this connection let's remark the commencement, which possessed music scientists some time ago, that music is aimed predominantly on the right brain hemisphere (leading emotionally) now is believed to be a bit exaggerated. In every particular case there are integrative factors: first, individual specifics and the psychological personality of a musician-performer, second, the space of fabula intonation (V.V. Medushevsky) and the typical dramatic and stylistic specifics of the music.

Let's come back now to the essential problem of interconnection and interaction of the artistic mood in instrumental technology. Following all the above, the stated method of performers teaching (declarative in its essence), the music unity principle (or completeness, as mentioned above) of the artistic and technical development (education or teaching) of a musician should be added by particular psychological sententions and pedagogical demands, essential for his realization of all kinds, forms and music levels. Yet we may believe that the real harmony of these practically opponent sides of mastery is hardly reached (except for great musicians), as everything that considers technology and techniques of performance is available to conscious analyses and categorical description, while the artistic-imagery, the poetry in performance (as in art in general) in a great way is connected to the area of the subconscious and creative intuition.

\section{CONCLUSION}

Let's try to conclude the above. We may consider that in Russian theoretic music studies and the science of music performance some steps were made in order to justify the necessity of the actualization of the issues of music content in education, the development of its artistic variability and intonation-expressive nature. Since it did not happen, today we have to state a notable gap between the practice of young musicians' preparation and modern methods of teaching from modern music, psychology and the teaching of arts area. The reasons are the following.

First, the existing scientific development of artistic music content obviously hasn't reached the condition of completeness and systematization, which would allow us to use them in the general practice of interpretation art and musicians' formation. That's why in this process not only all the achievements of modern science should be considered, but also all of the rich history of music performance. Secondly, there are reasons of a different kind which also require consideration. In particular, it is important to know that the variation phenomenon of the content of music composition and music in general as a kind of art can be real only on the basis of multiple personality developments spiritual, aesthetic, artistic and finally the musical one - as the culture for young musicians. Now here are some considerations of practical nature. The first steps, aimed to overcome the existing crisis of the content understanding of European (opus) music must be an organizational and methodological one.

We should combine the music science of our time for educational practice through existing means. Books, programs and manuals should be implemented in schools, colleges and universities. The issues of figurative music content should be prioritized in every form of work with young musicians. Particular methods should be developed everywhere.

We can recall B.L. Yavorsky's imperative, expressed in that time when he was the publishing house editor of "Muzgiz" and edited «Schools of playing» for different instruments. To order a theory» — he used to say, — «and implement it in every «School» [10]. As we see, this wish is still wanted.

\section{CONCLUSION}

In conclusion let us express a suggestion to improve the existing educational standards of all three chains of the music education by a new subject called «Music content» at school and one called «The theory of music content» at college and university. The implementation of such a subject at colleges and music departments of music universities is considered to be possible. 
As far as the three stages of professional performance education are concerned, especially children's music schools, a different method can be used. One can study the ideas and concepts, methodology and instruments of the content analysis of the contextual layer of music (particularly music phenomena, poetics and drama of compositions). At a college or a university music theory classes, aesthetic courses, psychology and pedagogics of musical activity such as specialty, ensemble, orchestra or conducting classes, methodology courses, performance history, etc. should be implemented.

Implementation of the same theoretically developed subject together with the keeping of a number of above mentioned subjects, in our view will hardly lead to the gap disappearance between the achievements of music science and wide performance-pedagogical practice. «No soul power can be satisfied only from the other powers» the outstanding Russian violinist A.F. Losev used to say, «since their general development should match the awakening of music feeling, otherwise the play and the artist's work will be limited to copying...» [quoted by: 2, 72]. These wise words should be considered.

\section{REFERENCES}

[1] Auger L.S. My violin playing school. Interpretation of violin classics. - M., 1965.

[2] Berlyanchik M. Educational training principles of the young violinist formation. $-\mathrm{SPb}, 2000$.

[3] Gaidamovich T. Mstislav Rostropovich. - M., 1969.

[4] Grigoriev V. Reminiscences // D.F. Oistrach. Reminiscences. Articles. Interviews. Letters. - M.: Music, 1978. - P. 75-85.

[5] Kogan G. On Intonation of the Content of the Piano Performance // Sov. Music. - 1975, N 11.

[6] Curt E. Romantic Harmony and its Crisis in "Tristan" by Wagner. M., 1975.

[7] Mozart L. Fundamental Violin School / Transl. Torson. - SPb, 1804.

[8] Tsypin G.M. Interviews with D.B. Shafran // Academy of Music. 1992, N 3.

[9] Shulpyakov O.F. Music Performance Technique and an Artistic Image. - L., 1986.

[10] Yavorsky B.L. From the note-books// Glinka's State Central Music Museum. F. 146, N 357.

[11] Yakoupova O.A. Alfred Corto's Performing, Pedagogical and Editorial Life. - Magnitogorsk, 1999. 